\title{
The Impact of the Radar-Sampling Volume on Multiwavelength Spaceborne Radar Measurements Using Airborne Radar Observations
}

\author{
Lukas Pfitzenmaier ${ }^{1, *,+}+\mathbb{D}$, Alessandro Battaglia $2,+(\mathbb{D}$ and Pavlos Kollias $1,3,+$ (D) \\ 1 Institute for Geophysics and Meteorology, University of Cologne, DEA23 05315 Cologne, Germany; \\ pavlos.kollias@stonybrook.edu \\ 2 National Centre for Earth Observation, University of Leicester, Leicester LE1 7RH, UK; ab474@leicester.ac.uk \\ 3 School of Marine and Atmospheric Sciences, Stony Brook University, Stony Brook, NY 11790, USA \\ * Correspondence: 1.pfitzenmaier@uni-koeln.de \\ + These authors contributed equally to this work.
}

Received: 29 July 2019; Accepted: 25 September 2019; Published: 28 September 2019

\begin{abstract}
Multiwavelength radar observations have demonstrated great potential in improving microphysical retrievals of cloud properties especially in ice and snow precipitation systems. Advancements in spaceborne radar technology have already fostered the launch in 2014 of the first multiwavelength radar system in space, while several future spaceborne multiwavelength radar concepts are under consideration. However, due to antenna size limitations, the sampling volume of spaceborne radars is considerably larger than those achieved by surface- and airborne-based radars. Here, the impact of these large sampling volumes in the information content of the Dual-Wavelength Ratio estimates at $\mathrm{Ka}-\mathrm{W}, \mathrm{Ku}-\mathrm{Ka}$ is investigated. High-resolution airborne multiwavelength radar observations during the Olympic Mountain Experiment (OLYMPEx) are used to perform retrievals of ice/snow characteristic particle size, such as mass-weighted particle diameter. To mimic the different satellite sampling volumes, a moving average is applied to the airborne measurements. The radar-observed variables (reflectivity and dual-wavelength ratios) and retrieved microphysical properties at the coarser resolution are compared against those at the original resolution. Our analysis indicates that future $\mathrm{Ka}-\mathrm{W}$ spaceborne radar missions should take into account the impact of the radar resolution volume on the retrieval of microphysical properties and avoid footprints larger than $2-3 \mathrm{~km}$.
\end{abstract}

Keywords: radar remote sensing; spaceborne radars; multi-frequency radar systems; different radar-sampling volumes; cloud ice microphysics

\section{Introduction}

Multiwavelength radar observations have the potential to provide complimentary and synergistic measurements of cloud and precipitation systems [1,2]. Radars operating at cm- and mm-wavelengths have differences in sensitivity and ability to penetrate precipitation. Thus, the complementary of multiwavelength radar observations refers to their combined capability of detecting both cloud and precipitation. Examples of such complimentary observations are ground-based observations from the US Department of Energy (DOE) Atmospheric Radiation Measurement (ARM) program [3,4], airborne observations from National Aerodynamics Space Administration (NASA) and coincident observations from NASA's CloudSat Cloud Profiling Radar (CPR) and NASA's Global Precipitation Mission (GPM) Dual-Frequency Precipitation Radar (DPR) [5-7].

In addition to their complementary nature, when available for the same sampling volume, multiwavelength radar observations can be used synergistically to improve the retrieval of cloud and 
microphysical properties. Scattering properties of $\mathrm{cm}$ - and $\mathrm{mm}$-size particles strongly depend on the wavelength of the impinging electromagnetic radiation with attenuation and scattering become more and more important when moving from $\mathrm{X}-(8-12 \mathrm{GHz})$ to W-band $(75-110 \mathrm{GHz})$ [8-10]. As a result, the received power at different frequencies differs because of differences in the backscattering mechanism of the targets (the so-called "non-Rayleigh effect", Bohren and Huffman [11]) and in the attenuation properties of the medium through which the electromagnetic wave has propagated. These differential properties (differential scattering and absorption) provide additional information (beyond the sixth moment of the particle size distribution that is provided by the radar reflectivity under the Rayleigh assumption) that can be used to constrain the retrieval of key hydrometeor population properties [12-17].

Dual and triple-wavelength radar observations require matched sampling volumes to target the same precipitation microphysics and sufficient number of samples and signal-to noise ratios to reduce the error in the radar reflectivity measurements for all the radars. The matching of sampling volumes of multiwavelength radar systems requires either different antenna sizes or sub-illumination of the reflector by the higher frequency radar system. The size of the radar antenna is not a tight constraint for ground-based multi-frequency radar systems so that matched sampling volumes and very high spatial resolutions can be achieved (Kollias et al. [3], Ellis and Vivekanandan [14]). Airborne multiwavelength radar systems, though typically limited in their antenna size, also provide high-resolution matched sampling volumes due to their proximity to the precipitation system. Observations from groundand airborne-based multiwavelength radars have been used in most past efforts to advance the development of sophisticated multiwavelength retrieval algorithms. From space, the GPM-DPR offers the first matched dual-wavelength radar observations. The antenna size constrains how narrow the antenna beamwidth can be at the lower frequency $\left(0.7^{\circ}\right.$ at $\left.13.4 \mathrm{GHz}\right)$, thus resulting in matched sampling volumes $5 \mathrm{~km}$ horizontal resolution. The $250 \mathrm{~m}$ vertical resolution is dictated by the pulse length, which is the same for both the $\mathrm{Ku}$ and the Ka radars. The large radar resolution volumes of spaceborne radars have two main drawbacks: first they smooth out the natural variability of the microphysical processes; second they may introduce biases induced by non-uniform beam filling (NUBF) effects. These effects are ubiquitous in space radar measurements and occur when large gradients of radar reflectivity are present within the field of view of the instrument: this can cause significant errors in the estimated microphysical properties [18-21].

Over the last ten years, advancements in radar technology have led to the development of several future spaceborne multiwavelength radar concepts with improved performance [22]. One of the challenges in accurate estimation of precipitation from spaceborne radars is to achieve adequate spatial resolution with reasonable-sized antennas. When considering multi-frequency radar observations, it is still unclear what are adequate spatial resolutions (and corresponding antenna sizes) that enable microphysical retrieval with acceptable uncertainties. Previous research focused on the impact of NUBF on rainfall rate and Doppler velocity estimation using single-frequency radar measurements [19,23,24]. Here, high-resolution airborne radar observations are used to investigate the impact of the size of the radar-sampling volume on spaceborne multiwavelength radar observations. Dual Wavelength Ratio $(D W R)$ estimates at Ka-W and Ku-Ka radar frequency pairs are estimated at different sampling volumes and their impact on ice/snow characteristic particle size retrievals such as mass-weighted particle diameter $\left(D_{m}\right)[1,6,25,26]$ is evaluated.

\section{Observations and Applied Data Post-Processing}

Currently, no satellite triple-frequency radar data set is available. Thus, we selected an airborne radar data set from the Olympic Mountain Experiment (OLYMPEx) which took place on the Olympic Peninsula of Washington State from November 2015 through February 2016, as part of the NASA's GPM ground validation program [27]. The goal of the OLYMPEx field campaign is to validate the precipitation algorithms of the NASA GPM-DPR for mid-latitude frontal precipitation systems and the characterization of precipitation over mountainous areas. The data analyzed here were acquired by 
the Airborne Third Generation Precipitation Radar (APR3) triple-wavelength radar system on board the NASA's DC-8 aircraft from an altitude of $12 \mathrm{~km}$ [28]. APR3 has three different radars installed measuring simultaneously at the frequencies of $13.9 \mathrm{GHz}(\mathrm{Ku}-\mathrm{band}), 35.6 \mathrm{GHz}$ (Ka-band) and 94.2 GHz (W-band). The radar data are checked for time synchronicity, matching volumes and are re-gridded to the same grid $[28,29]$ In this paper, only measurements performed at nadir with a vertical resolution of $30 \mathrm{~m}$ are used. Approximately seven hours of data from the flights on the 1st and 3rd December 2015 are analyzed for this study.

The APR3 radar data set were corrected for attenuation based on the 4D-interpolation from the Modern-Era Retrospective analysis for Research and Applications, version 2 (MERRA-2) reanalysis. Scattering-based DWR measurements require high radar returns from non-Rayleigh scatterers. Thus, a conservative filtering of low Signal-to-Noise (SNR) radar observations was applied to remove artifacts and radar returns with high uncertainty in the reported radar observables. The reflectivity measurements are calibrated using the sea surface return [30]. Since the focus of these study is related to ice hydrometeors data below the $0^{\circ}$-isotherm are deleted before being remapped on a common time-range grid.

Figure 1 shows an example of radar observations from the APR3 on 1st December during OLYMPEx. The observations depict a broad stratiform precipitation region with orographic enhancement with a bright band clearly visible at an altitude of $2 \mathrm{~km}$ in the $\mathrm{Ku}$ - and $\mathrm{Ka}$-band observations, while at W-band the bright is less visible and often becomes a dark band [31]. The features inside the black contours indicate the data used in this study from this particular flight corresponding to the ice phase and to good SNR. The radar reflectivities reported by the three radars exhibit large differences mainly due to non-Rayleigh scattering. At both edges of the ground track the mountainous surface return is visible in Figure 1 between $500 \mathrm{~km}$ to $550 \mathrm{~km}$ and from $840 \mathrm{~km}$ to $880 \mathrm{~km}$ by an enhanced surface echo. Enhanced $\mathrm{Ku}$ - and $\mathrm{Ka}$-band radar reflectivity values are observed between $520 \mathrm{~km}$ to $580 \mathrm{~km}$ (white box in Figure 1b). The enhanced radar returns can be attributed to the lifting of the air mass forced by the topographic barrier which leads to the formation of an environment favorable for rapid ice particle formation and growth [32]. In the region with less topographic influence $(550 \mathrm{~km}$ to $840 \mathrm{~km})$ the radar returns is less. The reflectivities depicted in Figure 1 clearly demonstrate the different sensitivities of the three radar frequencies. The least sensitive radar is the Ku-band $\left(Z_{K u}\right.$, Figure $1 \mathrm{a})$; the most sensitive radar is the Ka-band radar $\left(Z_{K a}\right.$, Figure $\left.1 \mathrm{~b}\right)$ followed by the $W$-band radar $\left(Z_{W}\right.$, Figure $\left.1 c\right)$. Clearly, the $W$-band radar signals are particularly attenuated by hydrometeors in the melting layer and by liquid stratiform precipitation below but the three radar reflectivities show large differences already in non-attenuated regions caused by non-Rayleigh scattering. These radar reflectivity differences form the basis for the estimation of the DWR signals. 

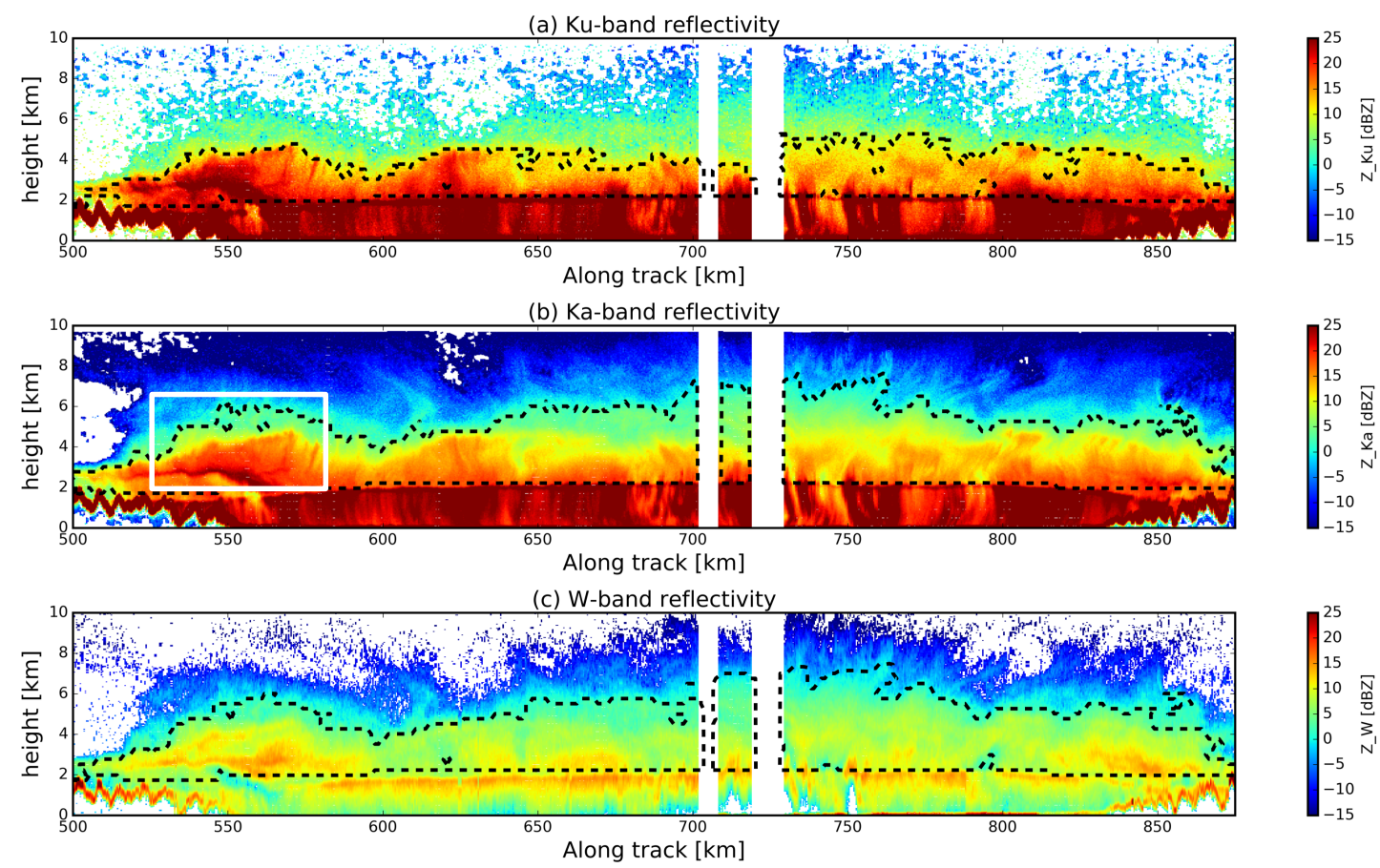

Figure 1. Reflectivity measurement from the OLYMPEx campaign, 1 December 2015, for Ku-band $\left(Z_{K u}\right.$, Panel (a)), for Ka-band $\left(Z_{K a}\right.$, Panel (b)), and for $W$-band $\left(Z_{W}\right.$, Panel (c)). The black contours mark the data used for the analysis. Observations below SNR threshold and below $0^{\circ}$-isotherm are filtered out.

\section{Methods}

In synopsis, the methodology used to assess the impact of different sampling volumes on ice microphysical retrievals consists of the following steps. We choose to average airborne measurements because, currently, no spaceborne triple-frequency measurement data set is available, the only multiple frequencies radar in space being GPM-DPR, the frequency of which are optimized to investigate liquid precipitation microphysics. Previous studies $[15,33,34]$ have demonstrated that triple-frequency observations are more suitable for the characterization of ice microphysics. Therefore, airborne measurements are used here to mimic satellite observations. First, the airborne resolution radar data are averaged along range and along track to simulate the dimensions of the sampling volume of spaceborne observations. Subsequently, the coarse resolution radar reflectivity at the three radar frequencies and the corresponding Ka-W and Ku-Ka DWR measurements are estimated. Next, a retrieval methodology is applied to retrieve mean mass-weighted diameters $\left(D_{m}\right)$ from $D W R$ s and Ice Water Contents (IWC) from radar reflectivity measurements. Finally, the microphysical retrievals at coarser sampling volumes are compared against those derived directly from the airborne high-resolution radar measurements using the same retrieval methodology and then averaged with the same procedure to the assumed spaceborne radar-sampling volumes. Details about the outlined methodology are provided in the next section.

\subsection{Simulation of Spaceborne Sampling Volumes from Field Campaign Data}

The spaceborne radar frequency and antenna size determine the antenna 3-dB beamwidth $\theta_{3 d B}$ and together with the satellite altitude determine the Instantaneous Field of View (IFOV) in the troposphere (lowest $12-20 \mathrm{~km}$ of the Earth's atmosphere). In addition to the IFOV, the satellite performs along track integration (limited to a small fraction of the IFOV), thus, the effective FOV is a smeared version of the antenna pattern. The effective FOV acts as a low-pass spatial filter, limiting the primary echo contributions to the observed received power to an area characterized by $\theta_{3 d B}$ and sets up the nominal 
horizontal resolution of the satellite. In addition to the horizontal resolution of the satellite, the radar pulse length determines the vertical resolution of the satellite [10].

Three spaceborne configurations (see Table 1) which we refer to as "current", "near-future" and "ideal" are considered in this study. The "current" configuration corresponds to the sampling volume of the GPM-DPR system, which is currently the only multi-frequency system operated in space [35]. The "near-future" configuration sampling volumes considered in the past and currently in proposed multiwavelength radar missions (e.g., the Aerosols, Clouds, Convection, and Precipitation mission The Decadal Survey [36]; the Polar Precipitation Mission (PPM), [37]). The "ideal" configuration represents a desirable but challenging to achieve upper limit in the resolution of the radar-sampling volume. This type of sampling volume is attainable only at the higher radar frequencies and may require the use of signal processing techniques such as deconvolution/reconstruction $[38,39]$ to increase the effective horizontal resolution of the spaceborne radar and, thus, allow the detection of smaller features.

To mimic the resolution of existing and proposed spaceborne radar systems a 2-D (vertical range and aircraft along track) spatial moving averaging window was used, to under-sample the high-resolved observations to the resolution of existing and proposed spaceborne radar systems

$$
\left\langle Z_{f}\right\rangle_{u}=10 \log _{10}\left(z_{f}\right)
$$

where $\left\langle Z_{f}\right\rangle$ is averaged reflectivity for the frequency $f$ at the satellite configuration $u=\{i=$ ideal; $n=$ near future; $c=$ current $\}$ of the original reflectivity $z_{f}$ in linear units $\left(\left\langle Z_{f}\right\rangle_{u}\right.$ in $d B Z, z$ in $\left.\mathrm{mm}^{6} / \mathrm{m}^{3}\right)$. The $2 \mathrm{D}$ spatial averaging window is shifted horizontally with a $1 \mathrm{~km}$ step.

Prior to applying the 2D spatial averaging window, the time dimension in the data is converted to horizontal distance. The averaged air-plane speed $\left(\overline{v_{e r}}=200 \mathrm{~m} \mathrm{~s}^{-1}\right)$ is used to convert time to horizontal length. The averaging procedure is illustrated in Figure 2.
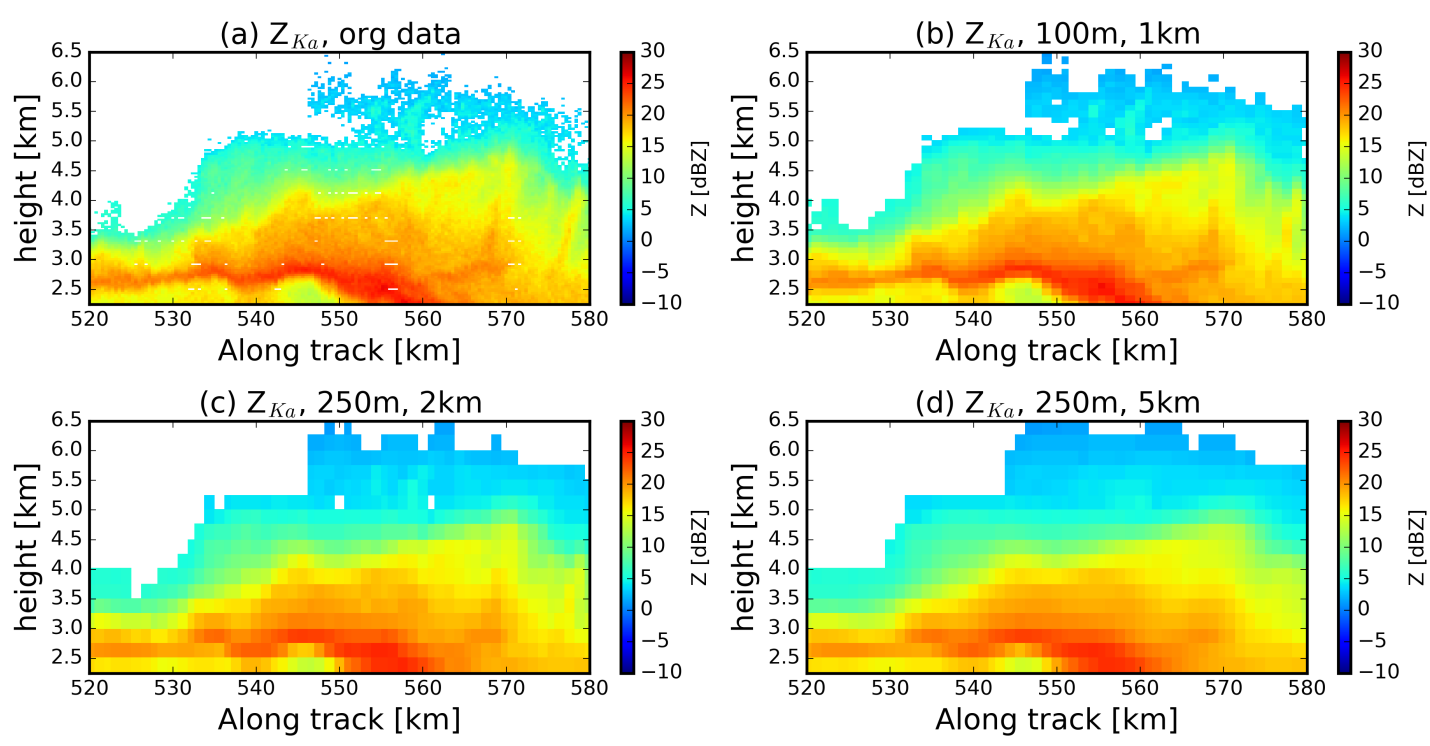

Figure 2. Example of the moving average window applied to the $Z_{K a}$ data from the OLYMPEx measurements highlighted in Figure $1 b$ (white box): (a) the original measured $Z_{K a}$ radar reflectivity with high resolution (see Table 1), (b): the radar reflectivity field at $100 \mathrm{~m}$ horizontal and $1 \mathrm{~km}$ vertical resolution, (c): the radar reflectivity field at $250 \mathrm{~m}$ horizontal and $2 \mathrm{~km}$ vertical resolution, (d): the radar reflectivity field at $250 \mathrm{~m}$ horizontal to $5 \mathrm{~km}$ vertical resolution.

Figure 2 shows results of the averaging procedure (in linear units) as applied to the original Ka-band reflectivity field (Figure $2 a$ ) within the area enclosed by the white box in Figure 1b). The procedure is repeated by shifting the $2 \mathrm{D}$ spatial averaging window by $1 \mathrm{~km}$. The plots show that the main feature of the Ka-band reflectivity field (enhanced radar reflectivity band) is maintained in all 
sampling resolutions. However, higher resolution Z-structures are smoothed (compare Figure 2a-d). The horizontal and vertical stretch of the hydrometeor echoes with decreasing resolution with consistent with previous studies [40]. These NUBF effects directly impact the estimated DWRs (their use is discussed in Leinonen et al. [1], Battaglia et al. [6], Hogan and Illingworth [25], Battaglia et al. [26]), and microphysical parameters such as the particle size distribution characteristic size derived from them (hereafter the mass-weighted particle diameter $\left(D_{m}\right)$ is used).

\subsection{Estimation of the Dual-Wavelength Ratios}

In Equation (2) the Dual-Wavelength Ratio for the different frequencies pairs is calculated using the averaged Z-fields,

$$
\left\langle D W R_{f_{1}, f_{2}}\right\rangle_{u}=\left\langle Z_{f_{1}}\right\rangle_{u}-\left\langle Z_{f_{2}}\right\rangle_{u},
$$

where $Z_{f_{1}}$ and $Z_{f_{2}}$ are reflectivities pairs, in dBZ space, at the two different frequencies $f_{1,2}$ with $f_{1}<f_{2}$. Figure 3 shows examples of calculated and post-processed $D W R_{K a W, u}$ corresponding to the $Z$-fields depicted in Figure 2. Overall, the $\left\langle D W R_{f_{1}, f_{2}}\right\rangle_{u}$ fields follow the behavior of the $\left\langle Z_{f}\right\rangle_{u}$-fields in Figure 2, i.e., a decrease of extreme values when coarsening the resolution. In contrast to the $Z$-fields, the $D W R_{K a W, u}$ fields show more gaps towards the cloud top, as a result of the reduced sensitivity of the $\mathrm{W}$-band radar in that region. Any negative DWRs attributed to NUBF and poor SNR conditions are discarded from further analysis. All the panels show an increase of the $\left\langle D W R_{f_{1}, f_{2}}\right\rangle_{u}$ with decreasing height which is obviously associated with aggregation processes and to the presence of larger particles in regions closer to the freezing level.

(a) DWR $\mathrm{DaW}_{K a}$, org data

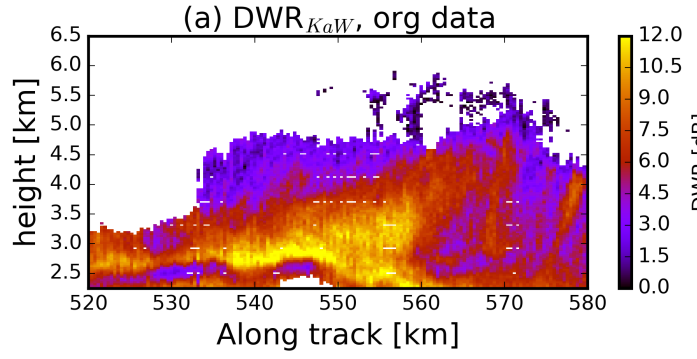

(c) DWR $\mathrm{DaW}_{K a}, 250 \mathrm{~m}, 2 \mathrm{~km}$

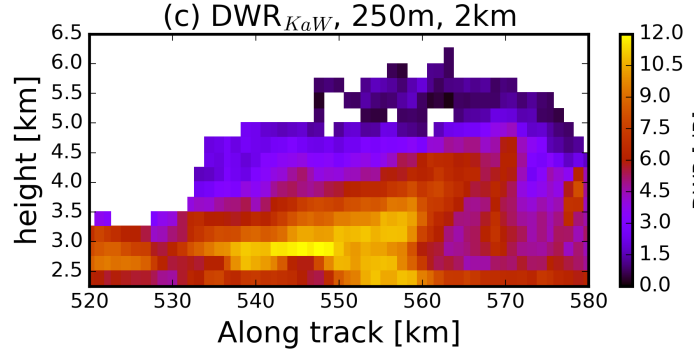

(b) $\mathrm{DWR}_{K a W}, 100 \mathrm{~m}, 1 \mathrm{~km}$

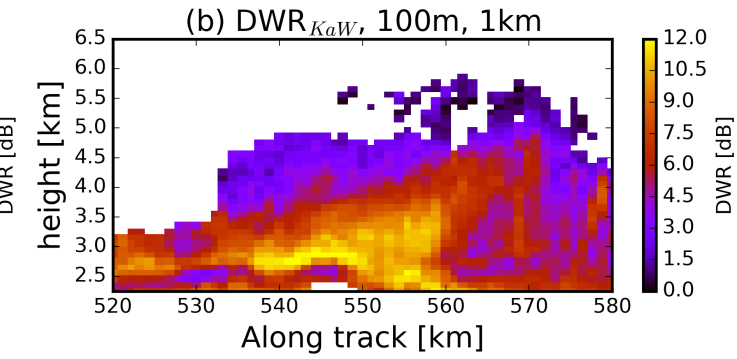

(d) $\mathrm{DWR}_{K a W}, 250 \mathrm{~m}, 5 \mathrm{~km}$

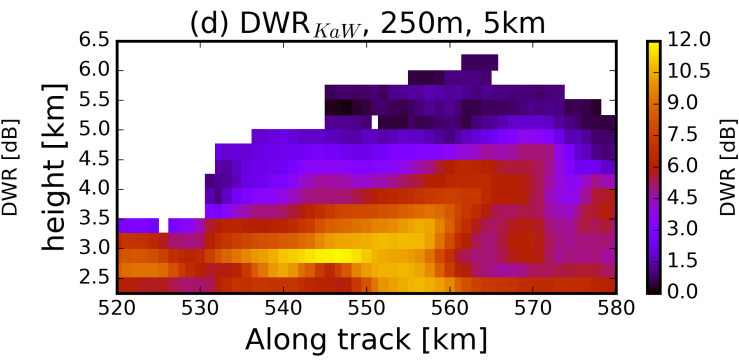

Figure 3. Example of $D W R_{K a W}$ at different resolutions from the OLYMPEx measurements highlighted in the white box of Figure 1b: (a) the original resolution, (b): at $100 \mathrm{~m}$ horizontal and $1 \mathrm{~km}$ vertical resolution, (c): at $250 \mathrm{~m}$ horizontal and $2 \mathrm{~km}$ vertical resolution, (d): at $250 \mathrm{~m}$ horizontal to $5 \mathrm{~km}$ vertical resolution.

The effect of the radar-sampling volume on the distribution of $D W R_{K u K a}$ and $D W R_{K a W}$ is shown in Figure 4 for the entire OLYMPEx dataset. Only radar reflectivity values above $0 \mathrm{dBZ}$ are used in the estimation of the $D W R$ values to ensure high quality signals. Furthermore, all points showing $D W R<0 \mathrm{~dB}$ are excluded in further analysis. The $D W R_{K a W}$ values exhibit higher dynamic range reaching values as high as $14-15 \mathrm{~dB}$ while the $D W R_{K u K a}$ values reach up to $8 \mathrm{~dB}$. The increasing averaging window causes the $D W R$ values to shift towards lower values. This shift is more pronounced in the case of the $D W R_{K a W}$ since these two frequencies are the most sensitive and NUBF is more 
effective in reducing the radar reflectivities especially near cloud edges. The effect is amplified for larger sampling volumes, e.g., for the $250 \mathrm{~m}-5 \mathrm{~km}$ volume.
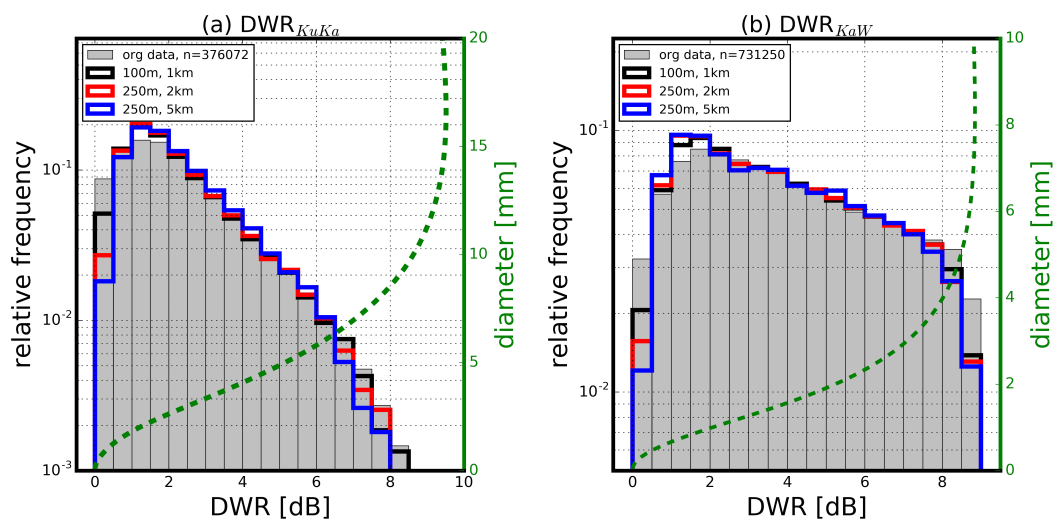

Figure 4. Histogram of $D W R_{K u K a}$ and $D W R_{K a W}$ for the original and coarser resolutions. (a) shows the histograms of the $D W R_{K u K a}$ and (b) the $D W R_{K a W}$ histograms. The gray area represents the normalized histogram of the original data, the lines represent the histograms of $100 \mathrm{~m}-1 \mathrm{~km}$ (black), $250 \mathrm{~m}-1 \mathrm{~km}$ (red), and $250 \mathrm{~m}-5 \mathrm{~km}$ (blue). The histograms are based on the OLYMPEx data from 1st and 3rd December 2015. The green dashed lines show the $D W R-D_{m}$ Look Up Tables used in this study.

\subsection{Microphysical Properties Retrieval}

This study focuses on the impact of the radar-sampling volume on multiwavelength radar retrievals of ice microphysical properties such as ice water content (IWC) and mean mass-weighted diameter $\left(D_{m}\right)$. The majority of radar-based observations of ice properties is based on single radar frequency measurements. Under these conditions, a widely used relationship to estimate the IWC is the one proposed by [41] that is based on radar reflectivity and temperature measurements as follows:

$$
\log _{10}\left(I W C_{K a, u}\right)=0.000242\left\langle Z_{K a}\right\rangle_{u}\langle T\rangle_{u}+0.0699\left\langle Z_{K a}\right\rangle_{u}-0.0186\langle T\rangle_{u}-1.63,
$$

In Equation (3) $\langle T\rangle_{u}$ is the temperature corresponding to the $\left\langle Z_{K a}\right\rangle_{u}$-volumes, and $I W C_{K a, u}$ the retrieved IWC based on Ka-band. The temperature profiles used in the calculation are from the MERRA-2 reanalysis data.

Hereafter we will use this relationship, to discuss the impact of the radar-sampling volume on single-frequency radar observations. In the case of multiwavelength radar observations, the retrieval of the $I W C$ is performed after the $D_{m}$ is estimated. Thus, the error in IWC in multiwavelength radar observations is a function of the error in the $D_{m}$ retrievals.

The multiwavelength $D_{m}$ retrievals are based on pre-computed Look Up Tables (LUT) of $D_{m}$ vs. DWR. LUT are computed by integrating ice crystal single scattering properties (e.g., extinction and backscattering cross section, single scattering albedo, asymmetry parameter) over the particle size distribution. Ice crystals are assumed to be described by exponential size distribution and can therefore be fully characterized by two properties. The methodology is affected by the ice scattering model which is assumed. Recent studies $[42,43]$ have shown that the distribution of the mass along the direction of the impinging radiation critically affects the backscattering properties of ice crystals. Once such a property is characterized on average for a population of "self-similar" ice crystals, then ice scattering properties are well described by the results of the self-similar Rayleigh Gans (SSRGA) approximation [44]. Depending on the morphology of the ice particles (maximum size, density, structure), the shape of the particle size distribution and the used scattering model, a number of 
relationships can be derived that related the $D W R$ to $D_{m}$. Each of the combination can lead to a different LUTs. The observed $D W R$ is linked to $D_{m}$ by Equation (4):

$$
\left\langle D_{m, f_{1} f_{2}}\right\rangle_{u}=\operatorname{LUT}\left(\left\langle D W R_{f_{1}, f_{2}}\right\rangle_{u}\right) .
$$

In this study, the relationship for the slightly rimed particles proposed by Leinonen and Szyrmer [45] is selected to demonstrate the effect of the radar-sampling volume to the $D_{m}$ estimation. Tridon et al. [28] demonstrated that this scattering model generally is the one that provides the best agreement between radar multi-frequency observations and in situ data during OLYMPEx. In Figure 4 the LUT based on Leinonen and Szyrmer [45] is shown as dashed green lines. The LUT clearly saturates at large values (i.e., points at $D W R \approx 9 \mathrm{~dB}$ ), which limit the retrieval of $D_{m}$ to $D_{m}$ smaller than $12 \mathrm{~mm}$ and $5 \mathrm{~mm}$ for the Ku-Ka and the Ka-W pairs, respectively. These plots demonstrate the complementary of the two frequency pairs here considered: the $D W R_{K a W}$ is optimal in retrieving particles between 1 and $5 \mathrm{~mm}$ whereas $D W R_{K u K a}$ particles in the range between 2 and $10 \mathrm{~mm}$.

It is worth noting that the selection of a single LUT causes already uncertainty into the retrievals of the $D_{m}$ because the LUTs depend on the different particle habits as a result of different growth processes. However, this study only aims at understanding uncertainties caused by coarsening the radar-sampling volumes.

An example of $I W C$ and $D_{m}$ retrievals at the airborne radar data resolution is depicted in Figure 5. The $D_{m}$ retrievals are based on the $D W R_{K a W}$ measurements. The dark areas in the $D_{m}$ retrievals correspond to regions where the LUT is saturated and the $D_{m}$ retrieval is ambiguous for they are available from this dual-wavelength ratio.
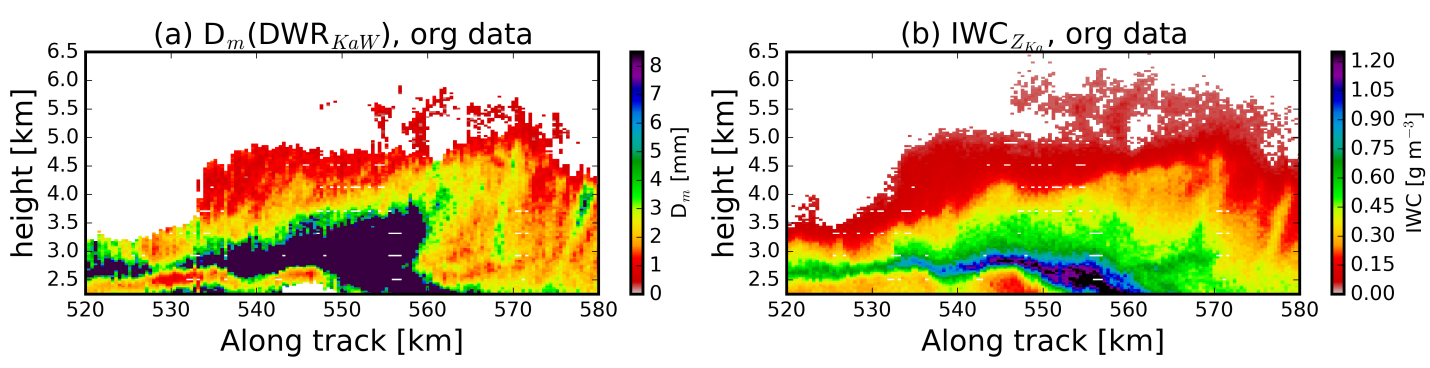

Figure 5. (a) Retrieved $D_{m}$ from the $D W R_{K a W}$ and (b) $I W C_{K a}$ for the original data resolution in correspondence to the OLYMPEx measurements highlighted in the white box of Figure 1b. In (a) the dark areas within the cloud are filtered out because the Look Up Tables for $D_{m}$ saturates at such large $D W R_{K a W}$-values

\section{Uncertainty and Biases in Microphysical Retrievals}

The impact of the radar-sampling volume on the ice and snow microphysical retrievals is evaluated in terms of uncertainty and biases. First, the microphysical retrievals of $I W C$ and $D_{m}$ are estimated for the entire dataset and for all the spaceborne radar resolutions listed in Table 1. Second, the coarse microphysical retrievals are interpolated back to the finer resolution (airborne observations). The relative error, $R E$, at each high-resolution point $(i, j)$ is estimated as in Equation (5):

$$
R E[i, j]_{u}=\frac{D_{m, f_{1} f_{2}}[i, j]_{u}-D_{m, f_{1} f_{2}}[i, j]}{D_{m, f_{1} f_{2}}[i, j]} \cdot 100 \% .
$$

Similar equations are used for the IWC. Finally, the distributions of the relative errors of the IWC and $D_{m}$ are presented as a function of different classes (bins) of $I W C$ and $D_{m}$. 
Table 1. Resolutions of the original dataset and of the sampling volumes of the different spaceborne configurations analyzed in this study.

\begin{tabular}{ccc}
\hline & \multicolumn{2}{c}{ Field Campaign Dataset } \\
\hline vertical & horizontal & airborne radar dataset \\
\hline $40 \mathrm{~m}$ & $400 \mathrm{~m}$ & OLYMPEx data set \\
\hline \multicolumn{3}{c}{ Spaceborne configurations } \\
\hline vertical & horizontal & configuration \\
\hline $100 \mathrm{~m}$ & $1.0 \mathrm{~km}$ & "ideal" configuration \\
$250 \mathrm{~m}$ & $2.0 \mathrm{~km}$ & "near-future" configuration \\
$250 \mathrm{~m}$ & $5.0 \mathrm{~km}$ & "current" configuration \\
\hline
\end{tabular}

Figure 6 shows the relative errors in the retrieved $D_{m}$ based on $D W R_{K u K a}$ and $D W R_{K a W}$ for all the spaceborne radar resolutions considered in this study. Mean values and percentiles of the relative errors are binned into eight $D_{m}$-bins from $0-1 \mathrm{~mm}$ to $D_{m}>7 \mathrm{~mm}$.
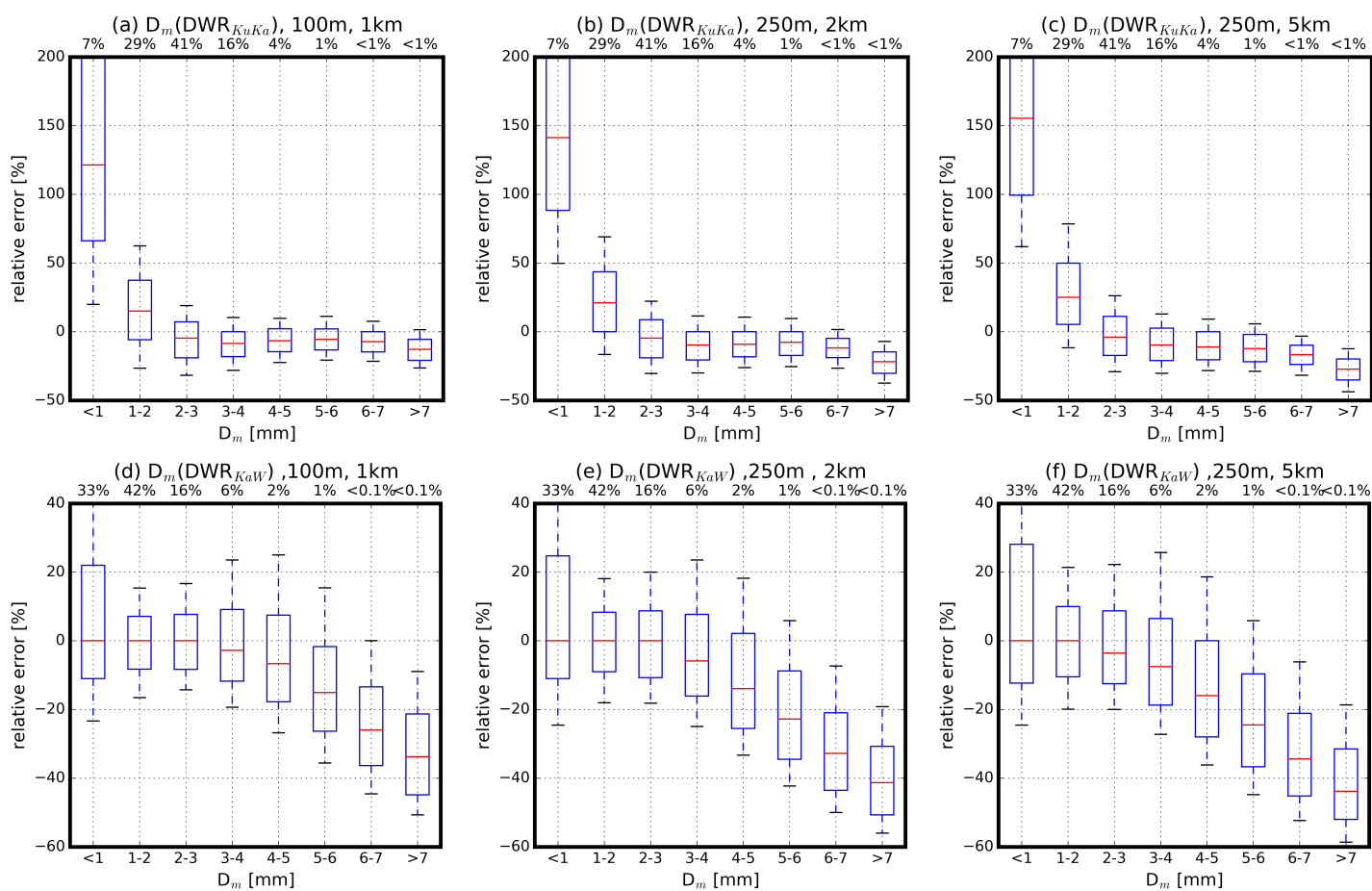

Figure 6. Box-plot of the retrieved $D_{m}$ as a function of relative error of $D_{m}$ for the coarser resolution to the mean $D_{m}$ on the original resolution. The $D_{m}$ is binned into $1 \mathrm{~mm}$ classes from $0-1 \mathrm{~mm}$ till $D_{m}>7 \mathrm{~mm}$, the data ticks show the percentages of data per class. The boxes cover the area from the 25 to the 75 percentile and the red bar shows the median and the dashed lines and bars denote the 10 and 90 percentile of the data in the class. (a-c) show the data based on $D W R_{K u K a}$ for all the resolutions. $(\mathbf{d}-\mathbf{f})$ show the data based on $D W R_{K a W}$ for all the resolutions. The resolutions are $100 \mathrm{~m}-1 \mathrm{~km}$, $250 \mathrm{~m}-1 \mathrm{~km}$, and $250 \mathrm{~m}-5 \mathrm{~km}$, respectively. Plots show results based on the combined OLYMPEx data.

For both $D W R$ pairs, the distributions of the relative errors show considerable spread and biases that are amplified as the size of the radar-sampling volume increases. The $D_{m}$ retrievals based on $D W R_{K u K a}$ measurements exhibit large biases (more than 100\%) and considerable uncertainty at the small $D_{m}$ sizes. This can be explained by the poor sensitivity of the $D W R_{K u K a}$ measurements to small particles and the considerable underestimation of the $D W R$ with increasing radar resolution (see Figure 4). At medium sizes, a small underestimation (5-10\%) of the $D_{m}$ is observed due to the 
overall small shift of the DWRs towards lower values with coarser resolutions. The $D_{m}$ bias become more pronounced at the very large $D_{m}$ values and for the larger sampling volumes.

The relative error distributions of the $D_{m}$ are quite different for the $D W R_{K a W}$ pair. The larger sensitivity of the $D W R_{K a W}$ to lower $D_{m}$ values, minimizes the impact of underestimation of the $D W R$ with increasing radar resolution. On the other hand, the $D_{m}$ retrievals exhibit considerable biases $(20-50 \%)$ at larger $D_{m}$ values. The biases are present at all radar resolutions and are enhanced for the coarser radar resolutions examined here.

The corresponding relative error distributions for the IWC for the three spaceborne radar-sampling volumes considered in this study are shown in Figure 7. The IWC retrievals are based on the Ka-band radar reflectivity and Equation (3) where the only radar input is the radar reflectivity factor. This relationship has been widely used when single-frequency radar observations are available. The impact of the radar resolution volume is small with biases within $\pm 10 \%$ at the low and high end of the retrieved IWC value. However, the validity of this approach is questionable. As already mentioned, there is a large (unaccounted) uncertainty related to the scattering model to represent the interaction of the radar signal with complex shape snowflakes. The aforementioned uncertainty can be reduced using dual-wavelength radar observations. In this case, the retrieval of the $I W C$ is performed after the determination of $D_{m}$ using the DWR measurements and the LUT. Thus, the $D_{m}$ measurement error, amplified by an exponent between 4 to 5 , depending on the scattering model used, controls the corresponding IWC error.
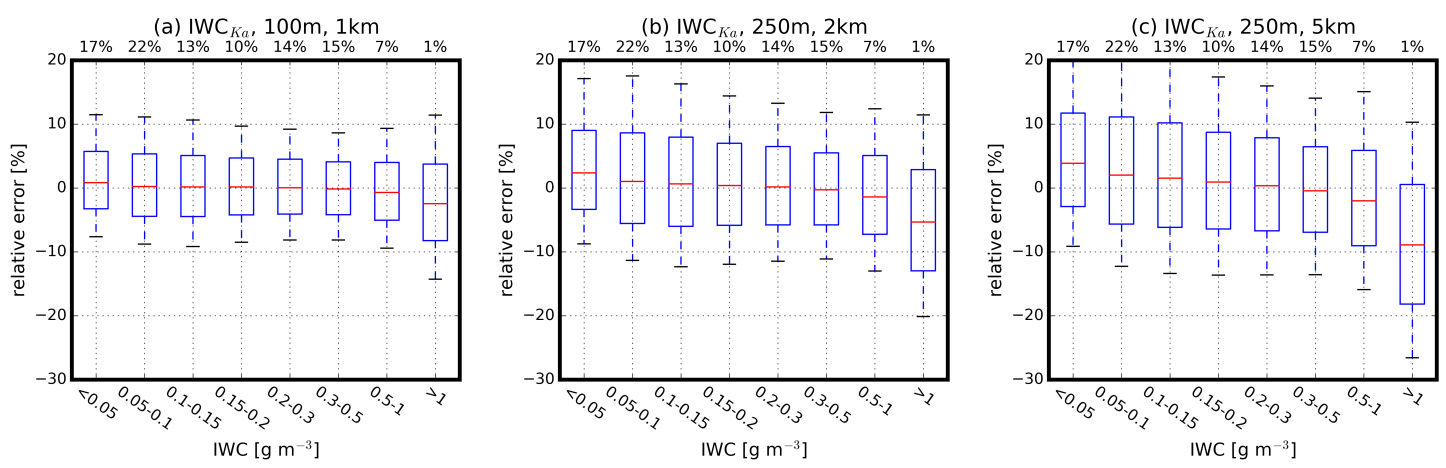

Figure 7. Box-plot of the relative error of the retrieved IWC as a function of different classes of IWC from $0-1.2 \mathrm{~g} \mathrm{~m}^{-3}$. The percentage of the points in each IWC class (out of the entire OLYMPEx dataset) is shown at the top of the figure for each spaceborne radar resolution depicted in (a) [100 m, $1 \mathrm{~km}]$, (b) $[250 \mathrm{~m}, 2 \mathrm{~km}]$ and (c) $[250 \mathrm{~m}, 5 \mathrm{~km}]$. The boxes cover the area from the 25 to the 75 percentile and the red bar shows the median and the dashed lines and bars denote the 10 and 90 percentile of the data in the class.

\section{Conclusions}

Due to their differences in sensitivity, attenuation and scattering by hydrometeors, multiwavelength radar observations have the potential to provide a holistic detection of cloud and precipitation systems. At the same time, the provided $D W R$ observations can be used to improve microphysical retrievals. Due to the high non-homogeneous nature of clouds and precipitation, high quality DWR measurements are needed which require matched sampling volumes. This is a challenging requirement especially from a spaceborne platform since the maximum size of the antenna defines the radar-sampling volume. Therefore, for the longer radar wavelength involved in multiwavelength radar measurements the antenna size determines the radar-sampling volume.

Here, the impact of the radar-sampling volume on the DWR estimation and subsequent microphysical parameters such as $I W C$ and $D_{m}$ is evaluated. Coarser resolution radar observations are generated by using fine resolution airborne multiwavelength radar observations from NASA'S OLYMPEx field experiment. These resolutions represent existing or planned future spaceborne radar 
systems. In general, averaging acts as a low-pass filter and removes large $D W R$ observed at the airborne fine resolution while generates also lower $D W R$ values due to non-uniform beam filling. The changes in the radar reflectivity distributions are also larger with increasing radar frequency.

The impact of the radar-sampling volume on $D_{m}$ depends on the specific LUT to convert DWR to $D_{m}$ and the selected dual-frequency radar pair for estimating the $D W R$. The shorter radar wavelength combination $D W R_{K a W}$-based estimates of $D_{m}$ exhibit robustness in the low $D_{m}$ region. On the other hand, the longer radar wavelength combination $D W R_{K u K a}$ exhibits robustness in the medium and large $D_{m}$ region. These difference in robustness is due to the different dynamic ranges in the relationship between $D_{m}$ and DWRs for different pairs of frequencies. This shows also that both DWR-pairs are needed to extend the range of retrieved $D_{m}$.

The coarser resolution [vertical,horizontal] tested here $[250 \mathrm{~m}, 5 \mathrm{~km}]$ corresponds to NASA's GPM-DPR resolution. This resolution has a small impact on the $D_{m}$ retrievals based on the $D W R_{K u K a}$. However, if a similar resolution is selected for a future Ka-W-band radar system in space, there will considerable biases in the $D_{m}$ retrievals. If measurements at all three radar frequencies are available, the biases and uncertainties introduced by the coarser spaceborne radar resolution can be adequately addressed with proper selection of the $D W R$ pair used for the $D_{m}$. However, achieving such triple-frequency radar observations from space remains a very challenging and costly proposition.

Author Contributions: In this Article the work was distributed under the authors as follows; conceptualization, A.B. and P.K.; methodology, A.B. and P.K.; software, L.P.; validation, L.P., A.B. and P.K.; writing一original draft preparation, P.K., A.B. and L.P.; visualization, L.P.; supervision, A.B.

Funding: This work was funded by was funded by the European Space Agency under the "Multi-frequency radar study" contract: 4000120689/17/NL/IA.

Acknowledgments: This work was funded by was funded by the European Space Agency under the "Multi-frequency radar study" contract: 4000120689/17/NL/IA.

Conflicts of Interest: All authors (L.P., A.B. and P.K.) declare no conflict of interest. The funders had no role in the design of the study; in the collection, analyses, or interpretation of data; in the writing of the manuscript, or in the decision to publish the results

\section{References}

1. Leinonen, J.; Lebsock, M.D.; Tanelli, S.; Suzuki, K.; Yashiro, H.; Miyamoto, Y. Performance assessment of a triple-frequency spaceborne cloud-precipitation radar concept using a global cloud-resolving model. AMT 2015, 8, 3493-3517, doi:10.5194/amt-8-3493-2015. [CrossRef]

2. Battaglia, A.; Tanelli, S.; Tridon, F.; Kneifel, S.; Leinonen, J.; Kollias, P. Satellite Precipitation Measurement; Chapter Triple-Frequency Radar Retrievals; Springer: Berlin, Germany, 2019; in press.

3. Kollias, P.; Bharadwaj, N.; Widener, K.; Jo, I.; Johnson, K. Scanning ARM Cloud Radars. Part I: Operational Sampling Strategies. J. Atmos. Ocean. Technol. 2014, 31, 569-582. [CrossRef]

4. Kollias, P.; Jo, I.; Borque, P.; Tatarevic, A.; Lamer, K.; Bharadwaj, N.; Widener, K.; Johnson, K.; Clothiaux, E.E. Scanning ARM Cloud Radars. Part II: Data Quality Control and Processing. J. Atmos. Ocean. Technol. 2014, 31, 583-598. [CrossRef]

5. Casella, D.; Panegrossi, G.; Sanò, P.; Marra, A.C.; Dietrich, S.; Johnson, B.T.; Kulie, M.S. Evaluation of the GPM-DPR snowfall detection capability: Comparison with CloudSat-CPR. Atmos. Res. 2017, 197, 64-75. [CrossRef]

6. Battaglia, A.; Mroz, K.; Lang, T.; Tridon, F.; Tanelli, S.; Heymsfield, G.; Tian, L. Using a multi-wavelength suite of microwave instruments to investigate the microphysical structure of deep convective cores. J. Geophys. Res. Atmos. 2016, doi:10.1002/2016JD025269. [CrossRef] [PubMed]

7. Tridon, F.; Battaglia, A.; Luke, E.; Kollias, P. Rain retrieval from dual-frequency radar Doppler spectra: Validation and potential for a midlatitude precipitating case-study. Q. J. R. Meteorol. Soc. 2017, 143, 1364-1380. [CrossRef]

8. Ulaby, F.T.; Haddock, T.F.; East, J.; Liepa, V. Millimeter-wave network analyzer-based scatterometer. In IGARSS '86: Remote Sensing: Today's Solutions for Tomorrow's Information Needs; IEEE: Piscataway, NJ, USA, 1986. 
9. Lhermitte, R. Attenuation and Scattering of Millimeter Wavelength Radiation by Clouds and Precipitation. J. Atmos. Ocean. Technol. 1990, 7, 464-479. [CrossRef]

10. Kollias, P.; Clothiaux, E.E.; Miller, M.A.; Albrecht, B.A.; Stephens, G.L.; Ackerman, T.P. MillimeterWavelength Radars: New Frontier in Atmospheric Cloud and Precipitation Research. Bull. Am. Meteorol. Soc. 2007, 88, 1608. [CrossRef]

11. Bohren, C.F.; Huffman, D.R. Absorption and Scattering of Light by Small Particles; John Wiley: Hoboken, NJ, USA, 1983; p. 530.

12. Hogan, R.J.; Kew, S.F. A 3D stochastic cloud model for investigating the radiative properties of inhomogeneous cirrus clouds. Q. J. R. Meteorol. Soc. 2005, 131, 2585-2608. [CrossRef]

13. Matrosov, S.Y.; Heymsfield, A.J.; Wang, Z. Dual-frequency radar ratio of nonspherical atmospheric hydrometeors. Geophys. Res. Lett. 2005, 32, L13816. [CrossRef]

14. Ellis, S.M.; Vivekanandan, J. Liquid water content estimates using simultaneous $\mathrm{S}$ and $\mathrm{K}_{a}$ band radar measurements. Radio Sci. 2011, 46, RS2021. [CrossRef]

15. Kneifel, S.; Lerber, A.; Tiira, J.; Moisseev, D.; Kollias, P.; Leinonen, J. Observed relations between snowfall microphysics and triple-frequency radar measurements. J. Geophys. Res. Atmos. 2015, 120, 6034-6055. [CrossRef]

16. Tridon, F.; Battaglia, A. Dual-frequency radar Doppler spectral retrieval of rain drop size distributions and entangled dynamics variables. J. Geophys. Res. Atmos. 2015, 120, 5585-5601. [CrossRef]

17. Leinonen, J.; Lebsock, M.D.; Tanelli, S.; Sy, O.O.; Dolan, B.; Chase, R.J.; Finlon, J.A.; von Lerber, A.; Moisseev, D. Retrieval of snowflake microphysical properties from multifrequency radar observations. Atmos. Meas. Tech. 2018, 11, 5471-5488. [CrossRef]

18. Kozu, T.; Iguchi, T. Nonuniform Beamfilling Correction for Spaceborne Radar Rainfall Measurement: Implications from TOGA COARE Radar Data Analysis. J. Atmos. Ocean. Technol. 1999, 16, 1722. [CrossRef]

19. Durden, S.L.; Tanelli, S. Predicted Effects of Nonuniform Beam Filling on GPM Radar Data. IEEE Geosci. Remote Sens. Lett. 2008, 5, 308-310. [CrossRef]

20. Short, D.; Nakagawa, K.; Iguchi, T. Reduction of Nonuniform Beam Filling Effects by Vertical Decorrelation: Theory and Simulations. J. Meteorol. Soc. Jpn. Ser. II 2013, 91, 539-543. [CrossRef]

21. Mroz, K.; Battaglia, A.; Lang, T.J.; Tanelli, S.; Sacco, G.F. Global Precipitation Measuring Dual-Frequency Precipitation Radar Observations of Hailstorm Vertical Structure: Current Capabilities and Drawbacks. J. Appl. Meteorol. Climatol. 2018, 57, 2161-2178. [CrossRef]

22. Tanelli, S.; Haddad, Z.S.; Im, E.; Durden, S.L.; Sy, O.O.; Peral, E.; Sadowy, G.A.; Sanchez-Barbetty, M. Radar concepts for the next generation of spacebome observations of cloud and precipitation processes. In Proceedings of the 2018 IEEE Radar Conference (RadarConf18), Oklahoma City, OK, USA, 23-27 April 2018; pp. 1245-1249. [CrossRef]

23. Tanelli, S.; Im, E.; Durden, S.L.; Facheris, L.; Giuli, D. The Effects of Nonuniform Beam Filling on Vertical Rainfall Velocity Measurements with a Spaceborne Doppler Radar. J. Atmos. Ocean. Technol. 2002, 19, 1019-1034.<1019:TEONBF>2.0.CO. [CrossRef]

24. Tokay, A.; D'Adderio, L.P.; Porcù, F.; Wolff, D.B.; Petersen, W.A. A Field Study of Footprint-Scale Variability of Raindrop Size Distribution. J. Hydrometeorol. 2017, 18, 3165-3179. [CrossRef]

25. Hogan, R.J.; Illingworth, A.J. The Potential of Spaceborne Dual-Wavelength Radar to Make Global Measurements of Cirrus Clouds. J. Atmos. Ocean. Technol. 1999, 16, 518-531. doi:10.1175/1520-0426(1999)016<0518:TPOSDW>2.0.CO;2. [CrossRef]

26. Battaglia, A.; Tanelli, S.; Heymsfield, G.; Tian, L. The Dual Wavelength Ratio knee: A signature of multiple scattering in airborne $\mathrm{K}_{u}-\mathrm{K}_{a}$ observations. J. Appl. Meteorol. Climatol. 2014, 53, 1790-1808. [CrossRef]

27. Houze, R.A., Jr.; McMurdie, L.A.; Petersen, W.A.; Schwaller, M.R.; Baccus, W.; Lundquist, J.D.; Mass, C.F.; Nijssen, B.; Rutledge, S.A.; Hudak, D.R.; et al. The Olympic Mountains Experiment (OLYMPEX). Bull. Am. Meteorol. Soc. 2017, 98, 2167-2188. [CrossRef] [PubMed]

28. Tridon, F.; Battaglia, A.; Chase, R.J.; Turk, F.J.; Leinonen, J.; Kneifel, S.; Mroz, K.; Finlon, J.; Bansemer, A.; Tanelli, S.; et al. The microphysics of stratiform precipitation during OLYMPEX: Compatibility between 3-frequency radar and airborne in situ observations. J. Geophys. Res. Atmos. 2019, 124, 8764-8792. [CrossRef] 
29. Durden, S.L.; Tanelli, S. GPM Ground Validation Airborne Precipitation Radar 3rd Generation (APR-3) OLYMPEX V2 [Indicate Subset Used]. Dataset Available Onlinefrom the NASA EOSDIS Global Hydrology Resource Center Distributed Active Archive Center, Huntsville; NASA Global Hydrology Resource Center DAAC: Huntsville, AL, USA, 2008; doi:10.5067/GPMGV/OLYMPEX/APR3/DATA201. [CrossRef]

30. Li, H.; Tang, J.; Peng, Y. Modeling and analysis of characteristics of clutter for hybrid bistatic space-based radar. In Proceedings of the International Conference on Space Information Technology, Wuhan, China, 4 January 2006; pp. 16-20. [CrossRef]

31. Kollias, P.; Albrecht, B. Why the melting layer radar reflectivity is not bright at $94 \mathrm{GHz}$. Geophys. Res. Lett. 2005, 32. [CrossRef]

32. Roe, G.H. Orographic Precipitation. Annu. Rev. Earth Planet. Sci. 2005, 33, 645-671. [CrossRef]

33. Mason, S.L.; Hogan, R.J.; Westbrook, C.D.; Kneifel, S.; Moisseev, D.; von Terzi, L. The importance of particle size distribution and internal structure for triple-frequency radar retrievals of the morphology of snow Atmos. Meas. Tech. 2019, 2019, 4993-5018. [CrossRef]

34. Barrett, A.I.; Westbrook, C.D.; Nicol, J.C.; Stein, T.H.M. Rapid ice aggregation process revealed through triple-wavelength Doppler spectrum radar analysis. Atmos. Chem. Phys. 2019, 19, 5753-5769. [CrossRef]

35. Hou, A.Y.; Kakar, R.K.; Neeck, S.; Azarbarzin, A.A.; Kummerow, C.D.; Kojima, M.; Oki, R.; Nakamura, K.; Iguchi, T. The Global Precipitation Measurement Mission. Bull. Am. Meteorol. Soc. 2014, 95, 701-722. [CrossRef]

36. The Decadal Survey (Ed.) Thriving on Our Changing Planet: A Decadal Strategy for Earth Observation from Space; The National Academies Press: Washington, DC, USA, 2017.

37. Joe, P.; Kidd, C.; Kollias, P.; Tanelli, S.; Moisseev, D.; Battaglia, A.; Koikinen, J.; Arbery, G.; Deligny, B.; Caubet, E.; et al. The Polar Precipitation Measurement mission. In Proceedings of the 6th European Conference on Radar Meteorology and Hydrology: Satellite radar measurements and hydro-meteorological applications, Sibiu, Romania, 6-10 September 2010.

38. Schutgens, N.; Donovan, D. Retrieval of atmospheric reflectivity profiles in case of long radar pulses. Atmos. Res. 2004, 72, 187-196. [CrossRef]

39. Long, D.; Brodzik, M. Optimum image formation for spaceborne microwave radiometerproducts. IEEE Trans. Geosci. Remote Sens. 2016, 54, 2763-2779. [CrossRef] [PubMed]

40. Burns, D.; Kollias, P.; Tatarevic, A.; Battaglia, A.; Tanelli, S. The performance of the EarthCARE Cloud Profiling Radar in marine stratiform clouds. J. Geophys. Res. Atmos. 2016, 121, 14. [CrossRef]

41. Hogan, R.J.; Mittermaier, M.P.; Illingworth, A.J. The Retrieval of Ice Water Content from Radar Reflectivity Factor and Temperature and Its Use in Evaluating a Mesoscale Model. J. Appl. Meteorol. Climatol. 2006, 45, 301-317. [CrossRef]

42. Leinonen, J.; Moisseev, D.; Nousiainen, T. Linking snowflake microstructure to multi-frequency radar observations. J. Geophys. Res. Atmos. 2013, 118, 3259-3270, doi:10.1002/jgrd.50163. [CrossRef]

43. Hogan, R.J.; Westbrook, C.D. Equation for the Microwave Backscatter Cross Section of Aggregate Snowflakes Using the Self-Similar Rayleigh-Gans Approximation. J. Atmos. Sci. 2014, 71, 3292-3301. [CrossRef]

44. Leinonen, J.; Kneifel, S.; Hogan, R.J. Evaluation of the Rayleigh-Gans approximation for microwave scattering by rimed snowflakes. Q. J. R. Meteorol. Soc. 2018, 144, 77-88. [CrossRef]

45. Leinonen, J.; Szyrmer, W. Radar signatures of snowflake riming: A modeling study. Earth Space Sci. 2015, 2, 346-358. [CrossRef]

(c) 2019 by the authors. Licensee MDPI, Basel, Switzerland. This article is an open access article distributed under the terms and conditions of the Creative Commons Attribution (CC BY) license (http:/ / creativecommons.org/licenses/by/4.0/). 